\title{
Cumulus expansion and glucose utilisation by bovine cumulus-oocyte complexes during in vitro maturation: the influence of glucosamine and follicle-stimulating hormone
}

\author{
Melanie L Sutton-McDowall, Robert B Gilchrist and Jeremy G Thompson \\ Research Centre for Reproductive Health, Department of Obstetrics and Gynaecology, The University of Adelaide, \\ The Queen Elizabeth Hospital, Woodville Road, Woodville, South Australia 5011, Australia
}

Correspondence should be addressed to J G Thompson; Email: jeremy.thompson@adelaide.edu.au

\begin{abstract}
Glucose is an important metabolite and its presence during in vitro oocyte maturation (IVM) can have profound effects on the oocyte's developmental capacity. We have demonstrated that glucose uptake increases over a $24 \mathrm{~h}$ IVM period, with most accounted for as L-lactate production. However, as maturation proceeds, L-lactate production remains constant, suggesting an alternative role for glucose metabolism. We hypothesised that in the latter stages of oocyte maturation, glucose not accounted for by L-lactate production is utilised for FSH-stimulated extracellular matrix (ECM) synthesis. To examine precursor utilisation for synthesis of ECM, bovine cumulus-oocyte complexes (COCs) were matured in $\pm \mathrm{FSH}$ and/or glucosamine (an alternative substrate of matrix components). Measurements included COC diameters, glucose consumption and L-lactate production in spent media and $\left[\mathrm{U}-{ }^{14} \mathrm{C}\right]$ glucose incorporation into ECM. FSH significantly stimulated both diameter and glucose consumption during 20-24 $\mathrm{h}$ maturation compared with unstimulated complexes, although co-incubation with glucosamine and FSH decreased total glucose consumption 1.7 -fold compared with FSH alone $(P<0.05)$. Furthermore, there was a linear relationship between glucose and L-lactate metabolism in the presence of glucosamine, suggesting that the majority of glucose was being utilised for L-lactate production via glycolysis. In the presence of glucosamine, twofold less $\left[\mathrm{U}-{ }^{14} \mathrm{C}\right]$ glucose was incorporated into matrix compared with COCs cultured without glucosamine. These results support the hypothesis that there is a link between glucose and glucosamine uptake in FSH-stimulated ECM synthesis. Furthermore, glucose has multiple fates within the COC during maturation and levels of utilisation are dependent on the composition of the maturation environment. Reproduction (2004) 128 313-319
\end{abstract}

\section{Introduction}

Within the follicle there are several different somatic cell phenotypes that surround the oocyte. It is now widely recognised that bi-directional communication between the oocyte and follicular somatic cells is fundamentally important for folliculogenesis and oocyte growth and maturation (Eppig 2001). The morphology of the cumulus vestment surrounding an oocyte is commonly used as selection criteria prior to in vitro maturation (IVM; Shioya et al. 1988, Madison et al. 1992, Lonergan et al. 1994, Goud et al. 1998) and the degree of expansion can be used as a morphological indicator of oocyte quality following maturation. It is contentious as to whether cumulus expansion is directly related to developmental capacity of the oocyte (Ali \& Sirard 2002, Luciano et al. 2004), although culture conditions that promote improved IVM generally also promote cumulus expansion, such as follicle-stimulating hormone (FSH) and macromolecule supplementation (Eyestone \& de Boer 1993, Choi et al. 2001). Furthermore, the presence of the cumulus vestment increases fertilisation rates compared with denuded oocytes (Tanghe et al. 2003).

The synthesis of extracellular matrix (ECM) by cumulus cells in the latter stages of oocyte maturation leads to mucification and cumulus expansion (Buccione et al. 1990). Injection of mice with radio-labelled substrates of ECM (namely $\left[{ }^{3} \mathrm{H}\right]$ glucosamine) post-human chorionic gonadotrophin (hCG) administration leads to rapid incorporation into the cumulus vestment compared with lower incorporation rates in cumulus-oocyte complexes (COCs) arrested at meiosis I (Fowler 1988). The major constituent and structural backbone of the ECM is hyaluronic acid, which can be synthesised from numerous compounds including glucosamine and glucose (Fig. 1; Salustri et al. 1989, Chen et al. 1990). 


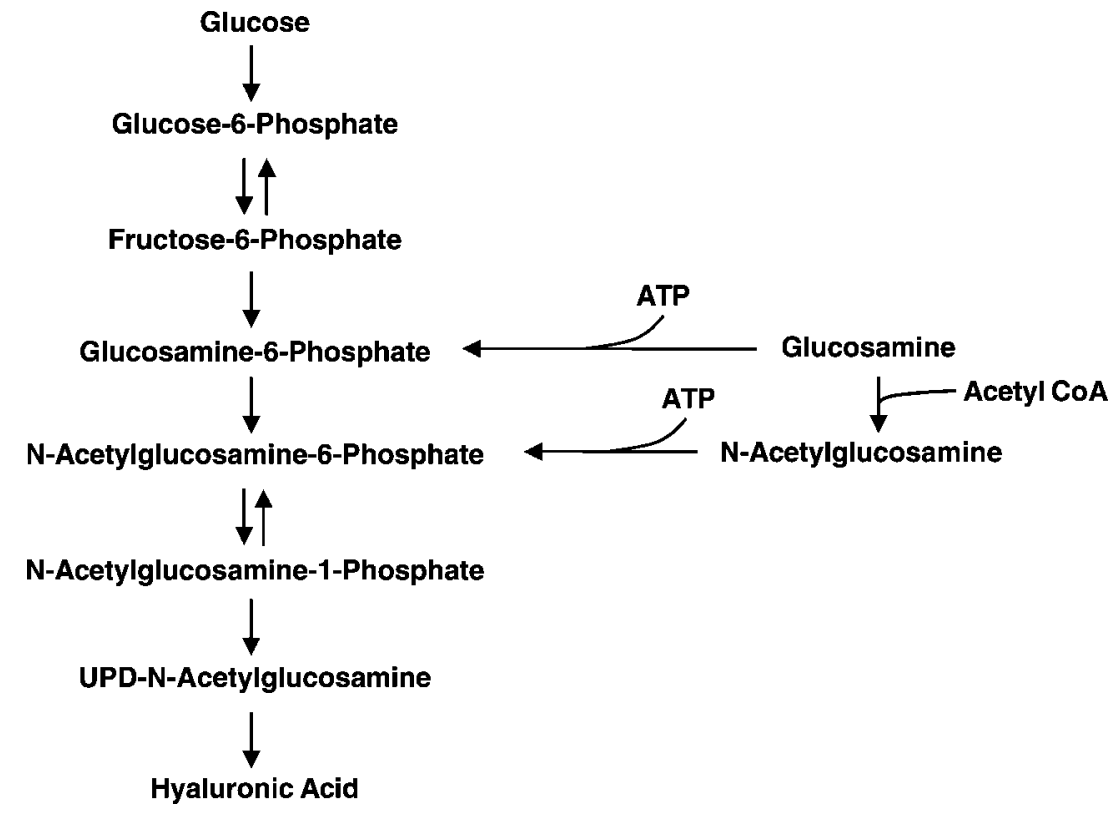

Figure 1 Hyaluronic acid synthesis from glucose and glucosamine.

Cumulus cells play a very important role in the utilisation of energy substrates during IVM (reviewed by Sutton et al. 2003b). In particular, the oocyte itself appears to lack the capacity for significant glucose uptake and utilisation (Biggers et al. 1967, Rieger \& Loskutoff 1994, Saito et al. 1994, Dan-Goor et al. 1997). Thus a major fate of glucose consumed by cumulus cells is its conversion to pyruvate or L-lactate via glycolysis, substrates that the oocyte can readily oxidise for energy in the form of ATP (Downs \& Utecht 1999, Khurana \& Niemann 2000a,b, Cetica et al. 2002). The metabolism of glucose also plays an important role in numerous other events throughout maturation. For example, metabolism of glucose through the pentose phosphate pathway plays a role in the regulation of meiotic progression through the production of substrates for purine nucleotide synthesis (Downs et al. 1998, Downs \& Hudson 2000). Additional products such as NADPH are involved in cytoplasmic integrity and pronuclear formation proceeding fertilisation (Urner \& Sakkas 1999). Indeed the presence and concentration of energy substrates, especially glucose, significantly affects oocyte developmental capacity (Krisher \& Bavister 1998).

We have previously demonstrated that as IVM of bovine COCs proceeds, glucose consumption increases but L-lactate production remains constant, suggesting an alternative fate for a proportion of the glucose consumed (Sutton et al. 2003a). FSH is an important stimulator of ECM synthesis (Salustri et al. 1989) and glucose consumption (Downs et al. 1996) by COCs, therefore it is plausible that during IVM a proportion of glucose could be converted to glucosamine and utilised for FSH-stimulated ECM synthesis and cumulus expansion. We hypothesise that during the course of IVM, glucose is increasingly utilised for matrix formation during FSH-stimulated mucification.
The aim of this study was to ascertain whether an increasing proportion of glucose during IVM is converted to matrix components by supplementing the culture media with glucosamine. A further objective was to characterise the influence of $\mathrm{FSH}$ on glucose utilisation during bovine IVM.

\section{Materials and Methods}

Unless specified, all chemicals and reagents were purchased from Sigma, St Louis, MO, USA.

\section{Oocyte collection and culture medium}

Bovine ovaries were collected from a local abattoir and transported to the laboratory in $30-35^{\circ} \mathrm{C}$ saline. Follicles between 3 and $8 \mathrm{~mm}$ in diameter were aspirated using an 18 -gauge needle and a $10 \mathrm{ml}$ syringe containing $\sim 1 \mathrm{ml}$ Handling media (HEPES buffered tissue culture medium 199; TCM199, ICN Biochemicals, Irvine, CA, USA, supplemented with $0.5 \mathrm{mM}$ sodium pyruvate and $4 \mathrm{mg} / \mathrm{ml}$ fatty acid-free BSA; ICPbio Ltd, Auckland, NZ). Intact COCs with compact cumulus vestments greater than three cell layers and ungranulated ooplasms were collected, washed twice in Handling media and once in the corresponding maturation media. Control medium (B-TCM199) was bicarbonate-buffered TCM199 supplemented with $0.5 \mathrm{mM}$ sodium pyruvate and $4 \mathrm{mg} / \mathrm{ml}$ fatty acid-free BSA.

\section{Experiment 1. The influence of FSH and glucosamine on glucose utilisation}

To determine the effect of glucosamine on glucose uptake, COCs were randomly divided into four treatment groups: (1) control medium (B-TCM199), (2) +FSH (B-TCM199 supplemented with $0.1 \mathrm{IU} / \mathrm{ml} \mathrm{FSH}$; Puregon; Organon, 
Oss, Netherlands), (3) + glucosamine (Glc) (B-TCM199 plus $5 \mathrm{mM}$ glucosamine) and (4) + FSH + Glc (B-TCM199 plus $0.1 \mathrm{IU} / \mathrm{ml} \mathrm{FSH}$ and $5 \mathrm{mM}$ glucosamine). COCs were cultured individually in $10 \mu \mathrm{l}$ drops of corresponding media, overlaid with mineral oil and incubated at $39^{\circ} \mathrm{C}$ with $6 \% \mathrm{CO}_{2}$ in humidified air. The concentration of glucosamine used has previously been shown to be an adequate concentration for cumulus expansion to occur in mouse, rat and sheep COCs (Chen et al. 1990).

COCs were transferred into fresh media and cultured individually in $2 \mu \mathrm{l}$ droplets at culture times $0-4 \mathrm{~h}$ and $20-24 \mathrm{~h}$. At the completion of culture, the horizontal and vertical diameters were measured using a dissecting microscope and ocular graticule. Spent media and COCs were stored individually in 96-well plates for DNA quantification and metabolite measurements respectively. Three experimental replicates were performed and a total of 15 COCs were assayed in each replicate for each treatment and time point.

\section{Experiment 2. $\left[\mathrm{U}_{-}{ }^{14} \mathrm{C}\right] \mathrm{Glucose}$ incorporation into extracellular matrix during cumulus expansion}

To determine whether exogenous glucose is converted to matrix components, COCs were cultured individually in $10 \mu \mathrm{l}$ pre-equilibrated drops of (1) -Glc (B-TCM199 plus $0.1 \mathrm{IU} / \mathrm{ml} \mathrm{FSH}, 0.1 \mathrm{IU} / \mathrm{ml} \mathrm{hCG}$ ) or (2) + Glc (B-TCM199 plus $0.1 \mathrm{IU} / \mathrm{ml} \mathrm{FSH}, 0.1 \mathrm{IU} / \mathrm{ml}$ hCG and $5 \mathrm{mM}$ glucosamine). Drops were overlaid with mineral oil and cultured at $39{ }^{\circ} \mathrm{C}$ with $6 \% \mathrm{CO}_{2}$ in humidified air. After $20 \mathrm{~h}$ of culture, COCs were washed and transferred into new media (B-TCM199 \pm glucosamine) containing $250 \mathrm{~Bq} / \mu \mathrm{l}$ $\left[\mathrm{U}-{ }^{14} \mathrm{C}\right]$ glucose (specific activity $=111 \mathrm{MBq} / \mathrm{mmol}$; Amersham Bioscience, UK). COCs were cultured individually in $10 \mu \mathrm{l}$ drops overlaid with mineral oil for a further $4 \mathrm{~h}$, after which COCs were washed and cultured in $10 \mu \mathrm{l}$ drops Handling medium for $1 \mathrm{~h}$. COCs were washed in Handling medium and within both groups, half of the COCs were transferred into $20 \mu \mathrm{l}$ Handling medium and the remaining half into $20 \mu \mathrm{l}$ Handling medium supplemented with $50 \mathrm{IU} / \mathrm{ml}$ hyaluronidase. COCs were vortexed and centrifuged to sediment the cells. Aliquots $(15 \mu \mathrm{l})$ of the supernatant were added to Eppendorf tubes containing $1 \mathrm{ml}$ scintillant (Opti Phase Supermix cocktail; EG\&G Wallac, Turku, Finland) and ${ }^{14} \mathrm{C}$ radioactivity was assessed using a Microbeta Trilux counter (EG\&G Wallac). Groups not exposed to hyaluronidase served as controls, whereas hyaluronidase treatment enabled the release of soluble $\left[U-{ }^{14} \mathrm{C}\right]$ glucose that was incorporated into the matrix; hence the proportion incorporated during culture could be determined. A total of 20 COCs were cultured per replicate and five COCs pooled per group. Three replicate experiments were performed.

\section{Experiment 3. Glucose depletion from IVM medium}

To assess the impact of IVM on glucose concentrations, a model for glucose depletion under standard culture conditions (i.e. control medium: B-TCM199 plus $0.1 \mathrm{IU} / \mathrm{ml}$ $\mathrm{FSH}$ and $0.1 \mathrm{IU} / \mathrm{ml} \mathrm{hCG}$ ) was created using Microsoft Excel version 7.0 software (Microsoft Corporation, Redmond, WA, USA), based on (1) a rate of glucose consumption determined previously (Sutton et al. 2003a), (2) initial glucose concentrations and (3) media density. The validity of the model was tested by culturing groups of 10 COCs in either $50 \mu \mathrm{l}(5 \mu \mathrm{l}$ per COC) or $100 \mu \mathrm{l}(10 \mu \mathrm{l}$ per COC) control medium or control medium supplemented with $5 \mathrm{mM}$ glucosamine $(+\mathrm{Glc})$. Pre-equilibrated culture drops were overlaid with mineral oil and were cultured at $39^{\circ} \mathrm{C}$ in $6 \%$ $\mathrm{CO}_{2}$ in humidified air. At $0 \mathrm{~h}, 18 \mathrm{~h}$ and $24 \mathrm{~h}, 2 \mu \mathrm{l}$ aliquots of media from the culture droplets were collected and stored in individual wells of a 96-well plate overlaid with mineral oil at $-80^{\circ} \mathrm{C}$. Glucose and L-lactate concentrations were measured as described below, to determine treatment effects on depletion of glucose and production of L-lactate. The experiment was replicated three times with each treatment being duplicated within each replicate.

\section{Glucose and L-lactate assays}

The total uptake of glucose and the production of L-lactate in the spent media were determined using microfluorometric assays that are based on measuring the production of $\mathrm{NADH}$ or $\mathrm{NADPH}$ at $340 \mathrm{~nm}$ using a fluorophotometric-inverted microscope (Leese \& Barton 1984). The fluorescence intensity of the spent media was then converted to substrate concentrations using standard curves that were conducted simultaneously.

\section{DNA assay}

The DNA content of individual COCs was quantified using PicoGreen dye (Molecular Probes, Eugene, OR, USA) to allow metabolic measurements to be expressed per ng DNA, hence accounting for variable cell numbers between complexes, as previously described (Sutton et al. 2003a).

\section{Statistical analyses}

Mean diameters, glucose consumption, L-lactate production and $\left[U-{ }^{14} \mathrm{C}\right]$ glucose counts were examined for treatment and time effects using two-way analysis of variance (ANOVA), followed by all pair-wise multiple comparison procedures (Tukey test). The relationship between glucose consumption and L-lactate production for all treatments was tested using linear regression analysis. All statistical tests were performed using SigmaStat version 2.0 computer software (SPSS Inc, Chicago, IL, USA).

\section{Results}

\section{Experiment 1. The influence of FSH and glucosamine on glucose utilisation}

To determine the metabolic fate of glucose, COCs were cultured with $\mathrm{FSH}$, a stimulator of cumulus expansion, 
and/or glucosamine, a substrate for hyaluronic acid. At time $0-4 \mathrm{~h}$ of culture, the diameters of the COCs were not affected by any of the treatments and were constant across all the groups (Table 1). Following $24 \mathrm{~h}$ of culture, the stimulatory effect of $\mathrm{FSH}$ was evident and there was a significant increase in COC diameter $(+\mathrm{FSH}=525.7 \pm$ $55.7 \mu \mathrm{m}$ and $+\mathrm{FSH}+\mathrm{Glc}=463.7 \pm 26.2 \mu \mathrm{m})$ compared with the control and COCs cultured with glucosamine alone $\quad$ control $=341 \pm 11.6 \mu \mathrm{m} \quad$ and $+\mathrm{Glc}=315.3 \pm$ $12.3 \mu \mathrm{m} ; P<0.05)$, where there was minimal cumulus expansion.

There were no significant differences between treatment groups in glucose consumption by COCs during $0-4 \mathrm{~h}$ culture $(P>0.05)$ (Fig. 2). Between 20-24h culture, the presence of glucosamine in the medium significantly decreased the consumption of glucose by COCs regardless of the presence or absence of $\mathrm{FSH}$ (main effects: $-\mathrm{Glc}=11.5 \pm 1.2 \mathrm{pmol} / \mathrm{ng} \mathrm{DNA} / \mathrm{h}$ vs $+\mathrm{Glc}=6.38 \pm$ $0.8 \mathrm{pmol} / \mathrm{ng} \mathrm{DNA} / \mathrm{h} ; P<0.05)$.

Significantly more L-lactate was produced by COCs in the presence of FSH compared with unstimulated complexes at both time points (Fig. 3). Over the 20-24 h culture period there was a significant interaction between glucosamine and FSH $(P<0.05)$ (Fig. 3). In the absence of glucosamine $\mathrm{FSH}$ caused a significant increase in L-lactate production relative to the control, whereas in the presence of glucosamine no differences in L-lactate production were observed in the presence or absence of $\mathrm{FSH}$.

\section{Experiment 2. $\left[\mathrm{U}_{-}{ }^{14} \mathrm{C}\right] \mathrm{Glucose}$ incorporation into extracellular matrix during cumulus expansion}

Individual COCs were cultured with $\left[U_{-}{ }^{14} \mathrm{C}\right]$ glucose in the presence or absence of glucosamine to determine whether glucose is converted to ECM and if exogenous glucosamine affects glucose consumption for ECM synthesis. Half of the treatment groups underwent hyaluronidase digestion to release any soluble $\left[\mathrm{U}_{-}{ }^{14} \mathrm{C}\right]$ glucose that was incorporated into the ECM. Both of the control groups that were not treated with hyaluronidase displayed similarly low levels of $\mathrm{U}-{ }^{14} \mathrm{C}$ carbon (most likely as glucose or glycolytic intermediates) within the COC supernatant, regardless of the presence or absence of glucosamine (Fig. 4). In contrast, significantly more $\mathrm{U}^{14} \mathrm{C}$ carbon was liberated from the ECM upon hyaluronidase digestion when COCs were cultured in media without glucosamine (- Glc + HA) compared with COCs cultured with glucosamine and treated with hyaluronidase $(-\mathrm{Glc}+\mathrm{HA}=6154 \pm 1623$ c.p.m. $/ 5$ COCs vs + Glc $+\mathrm{HA}=2828 \pm 1021$ c.p.m./5 COCs; $P<0.05$ ) (Fig. 4).

\section{Experiment 3. Glucose depletion from IVM medium}

A glucose depletion model was generated based on glucose consumption rates determined in previous experiments. We determined the validity of the model by culturing COCs in groups, utilising two densities of COCs per $\mu$ l maturation media. COCs were also cultured

Table 1 The diameters of cumulus-oocyte complexes (COCs) at $4 \mathrm{~h}$ and $24 \mathrm{~h}$ cultured in tissue culture medium 199 (B-TCM199, control) $\pm \mathrm{FSH}$ and/or \pm glucosamine $( \pm \mathrm{Glc})$. Values are means \pm S.E.M.

\begin{tabular}{lccrr}
\hline & \multicolumn{4}{c}{ Diameter $(\mu \mathrm{m})$} \\
\cline { 2 - 5 } Culture time $(\mathrm{h})$ & Control & $+\mathrm{FSH}$ & $+\mathrm{Glc}$ & $+\mathrm{FSH}+\mathrm{Glc}$ \\
\hline 4 & $316.9 \pm 13.8^{\mathrm{a}}$ & $310.9 \pm 12.3^{\mathrm{a}}$ & $295.4 \pm 6.12^{\mathrm{a}}$ & $314.2 \pm 12.3^{\mathrm{a}}$ \\
24 & $341.0 \pm 11.6^{\mathrm{b}}$ & $525.7 \pm 55.7^{\mathrm{c}}$ & $315.3 \pm 12.3^{\mathrm{b}}$ & $463.7 \pm 26.2^{\mathrm{c}}$ \\
\hline
\end{tabular}

Means with different superscripts within the same time are significantly different $(P<0.05)$.

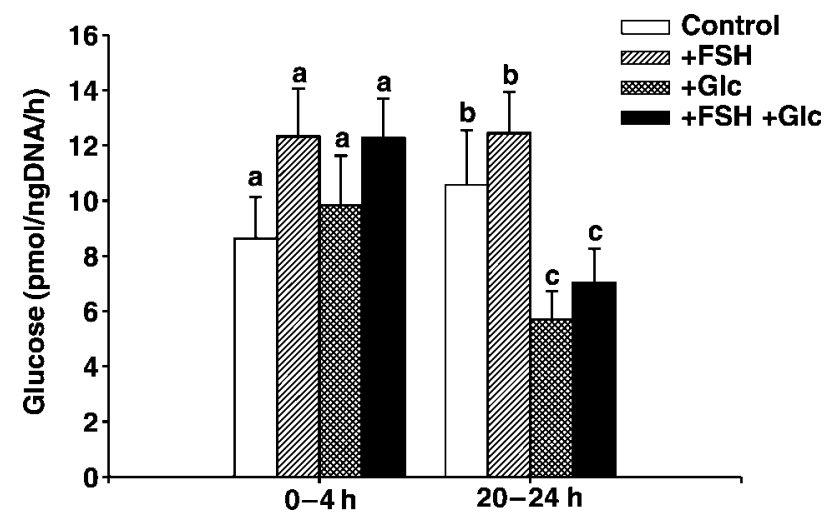

Figure 2 Glucose uptake by cumulus-oocyte complexes (COCs) from $0-4 \mathrm{~h}$ or $20-24 \mathrm{~h}$ of culture in control (TCM199),

$+\mathrm{FSH},+$ glucosamine (+ Glc) or + FSH+Glc. Data bars represent means \pm S.E.M. Means within a time period with different superscripts are significantly different $(P<0.05)$.

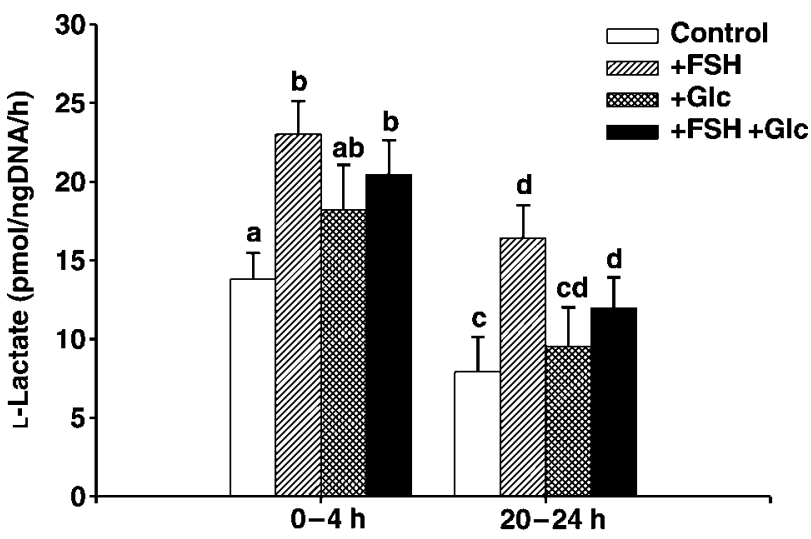

Figure 3 L-Lactate production by cumulus-oocyte complexes (COCs) from $0-4 \mathrm{~h}$ or $20-24 \mathrm{~h}$ of culture in control (TCM199),

$+\mathrm{FSH},+$ glucosamine $(+\mathrm{Glc})$ or $+\mathrm{FSH}+\mathrm{Glc}$. Data bars represent means \pm S.E.M. Means within a time period with different superscripts are significantly different $(P<0.05)$. 


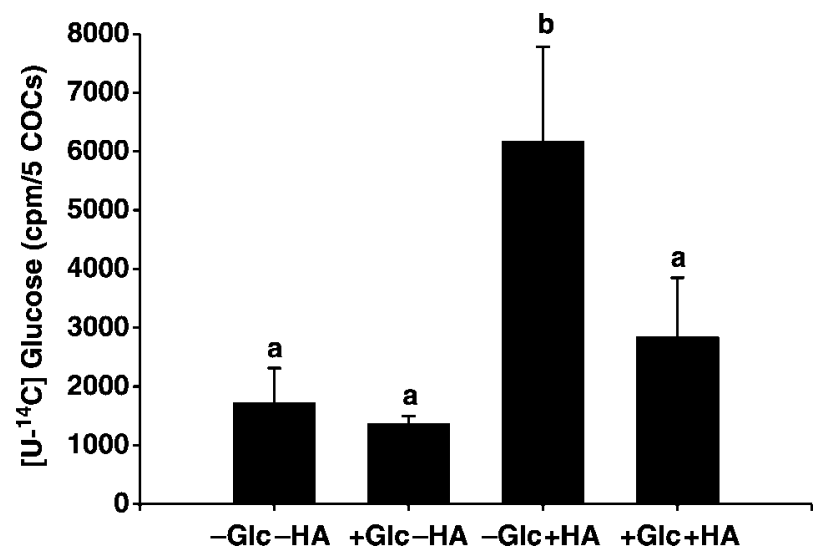

Figure $4\left[\mathrm{U}-{ }^{14} \mathrm{C}\right] \mathrm{Glucose}$ incorporation into extracellular matrix (ECM) by cumulus-oocyte complexes (COCs). COCs were cultured in media \pm glucosamine $( \pm \mathrm{Glc}$ ) and underwent post maturation treatment \pm hyaluronidase $( \pm \mathrm{HA})$ to determine whether glucosamine supplementation influences glucose incorporation into ECM. Data bars represent means \pm S.E.M. Bars with different superscripts are significantly different $(P<0.05)$.

in the presence or absence of glucosamine to determine whether glucosamine supplementation attenuated glucose loss from the maturation media.

When COCs were cultured at a density of $5 \mu \mathrm{l} / \mathrm{COC}$, the concentration of glucose remaining in media after $24 \mathrm{~h}$ in control media was similar to the concentration predicted by the glucose depletion model (Fig. 5A). Unlike the model where a linear rate of depletion was predicted, between $18 \mathrm{~h}$ and $24 \mathrm{~h}$ the concentration of glucose in both the control and the media supplemented with glucosamine remained unchanged. After $18 \mathrm{~h}$ and $24 \mathrm{~h}$ of culture, the presence of glucosamine led to a greater than 1.4-fold decrease in glucose uptake by COCs compared with the situation in control medium $(18 \mathrm{~h}$ : control $=1.80 \pm 0.29 \mathrm{mM}$ vs + Glc $=2.56 \pm 0.23 \mathrm{mM}$;
$24 \mathrm{~h}:$ control $=1.51 \pm 0.33 \mathrm{mM}$ vs $+\mathrm{Glc}=2.43 \pm$ $0.23 \mathrm{mM} ; P<0.05)$. Similar results were observed when COCs were cultured in $10 \mu \mathrm{l}$ medium per complex after $18 \mathrm{~h}$ (control $=3.05 \pm 0.19 \mathrm{mM}$ vs $+\mathrm{Glc}=3.79 \pm$ $0.17 \mathrm{mM} ; P<0.05)$ and $24 \mathrm{~h}$ (control $=2.68 \pm 0.24 \mathrm{mM}$ $\mathrm{vs}+\mathrm{Glc}=3.45 \pm 0.24 \mathrm{mM} ; P=0.05$ ) (Fig. 5B). However, under these conditions, glucose uptake followed the predicted rate of glucose depletion in medium containing glucosamine rather than the control groups (Fig. 5B). Furthermore, there was significantly less glucose in the $5 \mu \mathrm{l} / \mathrm{COC}$ culture system after $24 \mathrm{~h}$ of maturation compared with the $10 \mu \mathrm{l} / \mathrm{COC}(P<0.001)$, regardless of the presence or absence of glucosamine. With regards to L-lactate production, there were no significant differences between the control and the +glucosamine groups, regardless of culture time and the volume in which the COCs were cultured $(P>0.05)$ (Table 2).

\section{Discussion}

Although the roles of glucose and glucosamine in ECM synthesis and cumulus expansion are well known, especially in rodents, this is the first study directly to relate total glucose uptake to its role in cumulus-derived matrix synthesis via the glucosamine biosynthesis pathway. This study has demonstrated that the addition of glucosamine to culture medium leads to a decrease in total glucose uptake by bovine COCs during the final stages of IVM, coinciding with FSH-stimulated cumulus expansion. This was further validated by an experiment in which COCs cultured in media supplemented with glucosamine had reduced $U_{-}{ }^{14} \mathrm{C}$ carbon derived from glucose incorporated into their ECM compared with COCs cultured without glucosamine. Hence, bovine COCs preferentially utilise glucosamine over glucose for FSH-stimulated ECM synthesis.
A

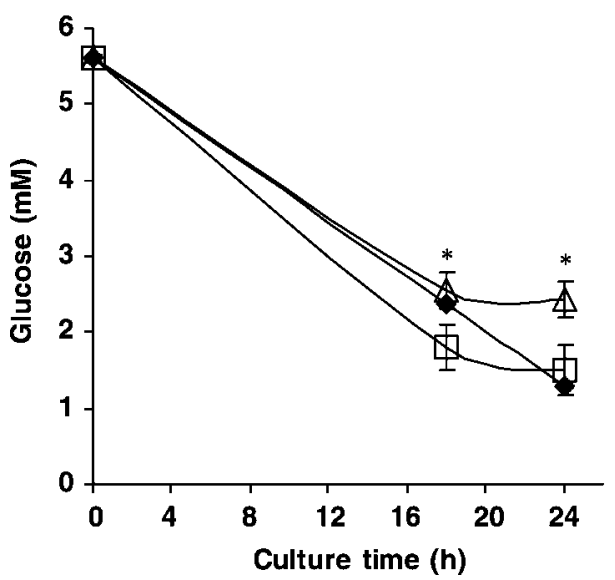

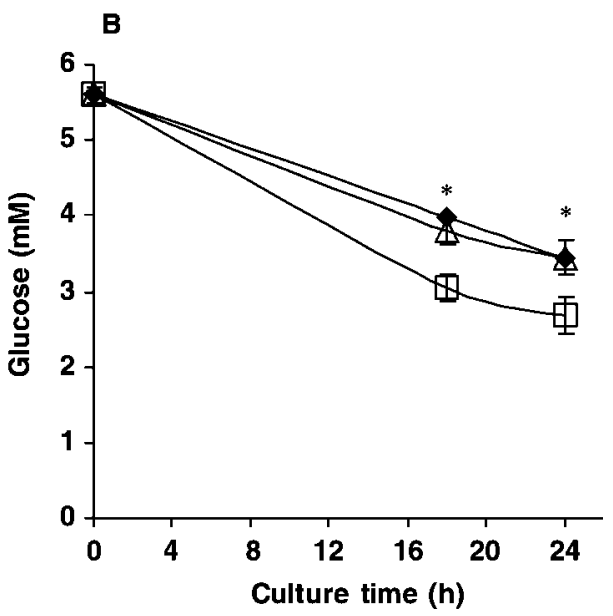

Figure 5 Glucose depletion from in vitro maturation (IVM) medium by 10 cumulus-oocyte complexes (COCs) cultured in either (A) $5 \mu$ l/COC or (B) $10 \mu \mathrm{l} / \mathrm{COC}$ and \pm glucosamine for $24 \mathrm{~h}$. ( ) Predicted depletion (based on modelling), ( $\square$ ) tissue culture medium 199 (B-TCM199, control), $(\triangle)+$ glucosamine $(+$ Glc). Data points represent means \pm S.E.M. $* P<0.05$ compared with control. 
Table 2 L-Lactate production by 10 cumulus-oocyte complexes (COCs) cultured at a concentiation of either $5 \mu \mathrm{l} / \mathrm{COC}$ or $10 \mu \mathrm{l} / \mathrm{COC}$ in tissue culture medium 199 (B-TCM199; control) or control + glucosamine $(+\mathrm{Glc})$. Values are means \pm S.E.M.

\begin{tabular}{|c|c|c|c|c|}
\hline \multirow[b]{3}{*}{ Culture time $(\mathrm{h})$} & \multicolumn{4}{|c|}{ L-Lactate production (mM) } \\
\hline & \multicolumn{2}{|c|}{$5 \mu \mathrm{l} / \mathrm{COC}$} & \multicolumn{2}{|c|}{$10 \mu \mathrm{l} / \mathrm{COC}$} \\
\hline & Control & + Glc & Control & + Glc \\
\hline 18 & $2.8 \pm 0.4$ & $2.5 \pm 0.4$ & $3.3 \pm 0.5$ & $2.2 \pm 0.3$ \\
\hline 24 & $2.9 \pm 0.4$ & $2.5 \pm 0.3$ & $3.7 \pm 0.5$ & $2.4 \pm 0.4$ \\
\hline
\end{tabular}

The results of this study demonstrate that supplementation of IVM media with glucosamine results in decreased glucose uptake by COCs cultured in both single and group culture systems. An investigation into the pattern of glucose depletion during maturation demonstrated that the density in which COCs are cultured alters the pattern of glucose metabolism. At high COC density (i.e. $5 \mu \mathrm{l} / \mathrm{COC})$, there appears to be a concentration-dependent plateau in glucose consumption and L-lactate production compared with the situation when lower densities (i.e. $10 \mu \mathrm{l} / \mathrm{COC}$ ) are used. This is significant as it suggests that glucose uptake and/or metabolism is inhibited at a time of significant demand. The addition of glucosamine only partly alleviates substantial glucose depletion, although maturing COCs at lower density combined with glucosamine was the most effective at maintaining a linear depletion of glucose from the media. Furthermore, the larger culture volume reduced L-lactate accumulation which may be associated with normal cellular function.

It is of interest to note that under maximal depletion conditions (i.e. high density and no glucosamine), glucose concentrations did not fall under $\sim 2.2 \mathrm{mM}$. We and others (Johnson et al. 2001, Berg et al. 2003, M L SuttonMcDowall, unpublished observations) have recently reported that bovine follicular fluid glucose levels are approximately $2.3 \mathrm{mM}$. We can only speculate why COCs matured under such conditions appear to inhibit glucose uptake. Perhaps atmospheric $\mathrm{pO}_{2}$ conditions present during IVM down-regulate glucose transporters, which are known to be regulated by oxygen concentration (Elvin et al. 1999). The exact time during IVM at which this decreased rate of glucose consumption occurs is not known since measurements of glucose concentrations were only performed in the latter period of the cultures.

A diverse range of media have been used for bovine IVM, with glucose concentrations ranging from $1.5 \mathrm{mM}$ in synthetic oviductal fluid (SOF; Ali \& Sirard 2002) to $28 \mathrm{mM}$ glucose in Waymouth MB 752/1 (Rose \& Bavister 1992). COCs cultured in substantially high glucose concentrations (10-28 mM glucose) have decreased ooplasmic glutathione levels (an important reducing agent), increased intracellular reactive oxygen species (Hashimoto et al. 2000) and compromised blastocyst development compared with COCs cultured in low to moderate glucose levels, such as SOF $(1.5 \mathrm{mM}$ or $5.6 \mathrm{mM}$ glucose;
Hashimoto et al. 2000), TCM199 and minimal essential medium (5.6 mM glucose; Rose \& Bavister 1992). Conversely, insufficient glucose during IVM leads to impaired completion of nuclear maturation (Hashimoto et al. 2000), cumulus expansion and blastocyst development (Rose-Hellekant et al. 1998), most likely due to insufficient substrates for hyaluronic acid synthesis. Although it is evident that glucose concentrations play a crucial role in oocyte maturation, the effects of culturing COCs in more physiological glucose concentrations have yet to be elucidated.

Supplementation of media with glucosamine reduces the requirement for glucose for matrix components. Glucosamine supplementation during IVM may be a mechanism through which glucose levels can be reduced to more physiological concentrations while providing the cumulus vestment with adequate substrates for mucification. Decreasing glucose concentrations have been shown to regulate the rate of meiotic resumption of murine COCs (Downs et al. 1998, Downs \& Hudson 2000).

In conclusion, we have demonstrated that a proportion of glucose uptake is linked to FSH-stimulated cumulus expansion during IVM. Glucosamine can assist in preventing significant glucose depletion in IVM media during maturation by providing an alternative and preferential substrate for matrix production and cumulus expansion.

\section{Acknowledgements}

We would like to thank Rachel Collett and Chris Kraft for technical assistance and ovary collections and Fred Armato and Svjetlana Kireta for advice and assistance with the $\left[\mathrm{U}-{ }^{14} \mathrm{C}\right.$ ]glucose experiment. M L S-M is supported by the Australia Research Council (SPIRT, C00107702) and Cook Australia Pty Ltd.

\section{References}

Ali A \& Sirard MA 2002 Effect of the absence or presence of various protein supplements on further development of bovine oocytes during in vitro maturation. Biology of Reproduction $\mathbf{6 6}$ 901-905.

Berg DK, Beaumont SE, Berg MC, Hull CD \& Tervit HR 2003 Oxygen and carbon dioxide tension in days 14-15 dominant bovine follicles measured in vivo or 4 hours post-mortem. Theriogenology $\mathbf{5 9}$ 406.

Biggers JD, Whittingham DG \& Donahue RP 1967 The pattern of energy metabolism in the mouse oocyte and zygote. Zoology $\mathbf{5 8}$ $560-567$

Buccione R, Schroeder AC \& Eppig JJ 1990 Interactions between somatic cells and germ cells throughout mammalian oogenesis. Biology of Reproduction 43 543-547.

Cetica P, Pintos L, Dalvit G \& Beconi M 2002 Activity of key enzymes involved in glucose and triglyceride catabolism during bovine oocyte maturation in vitro. Reproduction 124 675-681.

Chen L, Wert SE, Hendrix EM, Russell PT, Cannon M \& Larsen WJ 1990 Hyaluronic acid synthesis and gap junction endocytosis are necessary for normal expansion of the cumulus mass. Molecular Reproduction and Development 26 236-247.

Choi YH, Carnevale EM, Seidel GE Jr \& Squire EL 2001 Effects of gonadotropins on bovine oocytes matured in TCM-199. Theriogenology 56 661-670. 
Dan-Goor M, Sasson S, Davarashvili A \& Almagor M 1997 Expression of glucose transporter and glucose uptake in human oocytes and preimplantation embryos. Human Reproduction 12 2508-2510.

Downs SM \& Utecht AM 1999 Metabolism of radiolabeled glucose by mouse oocytes and oocyte-cumulus cell complexes. Biology of Reproduction 60 1446-1452.

Downs SM \& Hudson ED 2000 Energy substrates and the completion of spontaneous meiotic maturation. Zygote 8 339-351.

Downs SM, Humpherson PG, Martin KL \& Leese HJ 1996 Glucose utilization during gonadotropin-induced meiotic maturation in cumulus cell-enclosed mouse oocytes. Molecular Reproduction and Development 44 121-131.

Downs SM, Humpherson PG \& Leese HJ 1998 Meiotic induction in cumulus cell-enclosed mouse oocytes: involvement of the pentose phosphate pathway. Biology of Reproduction 58 1084-1094.

Elvin JA, Clark AT, Wang P, Wolfman NM \& Matzuk MM 1999 Paracrine actions of growth differentiation factor-9 in the mammalian ovary. Molecular Endocrinology 13 1035-1048.

Eppig JJ 2001 Oocyte control of ovarian follicular development and function in mammals. Reproduction 122 829-838.

Eyestone WH \& de Boer HA 1993 FSH enhances developmental potential of bovine oocytes matured in chemically defined medium. Theriogenology 39216.

Fowler RE 1988 An autoradiographic study of gonadotrophin regulation of labelled glycoconjugates within preovulatory mouse follicles during the final stages of oocyte maturation, using $\left[{ }^{3} \mathrm{H}\right]$ glucosamine as the radioactive precursor. Journal of Reproduction and Fertility 83 759-772.

Goud PT, Goud AP, Qian C, Laverge H, Van der Elst J, De Sutter P \& Dhont M 1998 In-vitro maturation of human germinal vesicle stage oocytes: role of cumulus cells and epidermal growth factor in the culture medium. Human Reproduction 13 1638-1644.

Hashimoto S, Minami N, Yamada M \& Imai H 2000 Excessive concentration of glucose during in vitro maturation impairs the developmental competence of bovine oocytes after in vitro fertilization: relevance to intracellular reactive oxygen species and glutathione contents. Molecular Reproduction and Development 56 520-526.

Johnson AE, Lane M, Gardner DK, Diekman MA \& Krisher RL 2001 Changes in follicular fluid environment between $5 \mathrm{~mm}$ and $10 \mathrm{~mm}$ follicles. Annual Conference of the Society for the Study of Reproduction, Ontario, Canada. Abstract 128.

Khurana NK \& Niemann H 2000a Effects of oocyte quality, oxygen tension, embryo density, cumulus cells and energy substrates on cleavage and morula/blastocyst formation of bovine embryos. Theriogenology $54741-756$.

Khurana NK \& Niemann H 2000 b Energy metabolism in preimplantation bovine embryos derived in vitro or in vivo. Biology of Reproduction 62 847-856.

Krisher RL \& Bavister BD 1998 Responses of oocytes and embryos to the culture environment. Theriogenology 49 103-114.

Leese HJ \& Barton AM 1984 Pyruvate and glucose uptake by mouse ova and preimplantation embryos. Journal of Reproduction and Fertility 72 9-13.
Lonergan P, Monaghan P, Rizos D, Boland MP \& Gordon I 1994 Effect of follicle size on bovine oocyte quality and developmental competence following maturation, fertilization, and culture in vitro. Molecular Reproduction and Development 37 48-53.

Luciano AM, Modina S, Vassena R, Milanesi E, Lauria A \& Gandolfi F 2004 Role of intracellular cyclic adenosine $3^{\prime}, 5^{\prime}$ monophosphate concentration and oocyte-cumulus cells communications on the acquisition of the developmental competence during in vitro maturation of bovine oocyte. Biology of Reproduction 70 465-472.

Madison V, Avery B \& Greve T 1992 Selection of immature bovine oocytes for developmental potential in vitro. Animal Reproduction Science 27 1-11.

Rieger D \& Loskutoff NM 1994 Changes in the metabolism of glucose, pyruvate, glutamine and glycine during maturation of cattle oocytes in vitro. Journal of Reproduction and Fertility $\mathbf{1 0 0}$ $257-262$.

Rose TA \& Bavister BD 1992 Effect of oocyte maturation medium on in vitro development of in vitro fertilized bovine embryos. Molecular Reproduction and Development 31 72-77.

Rose-Hellekant TA, Libersky-Williamson EA \& Bavister BD 1998 Energy substrates and amino acids provided during in vitro maturation of bovine oocytes alter acquisition of developmental competence. Zygote 6 285-294.

Saito T, Hiroi M \& Kato T 1994 Development of glucose utilization studied in single oocytes and preimplantation embryos from mice. Biology of Reproduction 50 266-270.

Salustri A, Yanagishita M \& Hascall VC 1989 Synthesis and accumulation of hyaluronic acid and proteoglycans in the mouse cumulus cell-oocyte complex during follicle-stimulating hormone-induced mucification. Journal of Biological Chemistry 264 13840-13847.

Shioya Y, Kuwayama M, Fukushima M \& Iwasaki S 1988 In vitro fertilization and cleavage capability of bovine follicular oocytes classified by cumulus cells and matured in vitro. Theriogenology $\mathbf{3 0}$ 489-496.

Sutton ML, Cetica PD, Beconi MT, Kind KL, Gilchrist RB \& Thompson JG 2003a Influence of oocyte-secreted factors and culture duration on the metabolic activity of bovine cumulus cell complexes. Reproduction 126 27-34.

Sutton ML, Gilchrist RB \& Thompson JG 2003b Effects of in-vivo and in-vitro environments on the metabolism of the cumulus-oocyte complex and its influence on oocyte developmental capacity. Human Reproduction Update 9 35-48.

Tanghe S, Van Soom A, Mehrzad J, Maes D, Duchateau L \& de Kruif A 2003 Cumulus contributions during bovine fertilization in vitro. Theriogenology 60 135-149.

Urner F \& Sakkas D 1999 A possible role for the pentose phosphate pathway of spermatozoa in gamete fusion in the mouse. Biology of Reproduction 60 733-739.

Received 8 March 2004

First decision 26 May 2004

Accepted 1 June 2004 